\title{
UMA SÍNTESE DA CONTRIBUIÇÃO DO GÊNERO Pinus PARA O DESENVOLVIMENTO SUSTENTÁVEL NO SUL DO BRASIL
}

\author{
André Germano Vasques*, Alex Sandro Nogueira**, Flávio Felipe Kirchner***, Ricardo Berger**** \\ *Eng. Florestal, M.Sc., Doutorando em Engenharia Florestal, UFPR - agvcwb@hotmail.com \\ **Eng. Florestal, Mestrando em Engenharia Florestal, UFPR - alexsandro@ufpr.br \\ ***Eng. Florestal, Dr., Depto. de Ciências Florestais, UFPR - kirchner@floresta.ufpr.br \\ ****Eng. Florestal, Dr., Depto. de Economia Rural e Extensão, UFPR - berger@ufpr.br \\ Recebido para publicação: 16/10/2006 - Aceito para publicação: 26/04/2007
}

\begin{abstract}
Resumo
A silvicultura do gênero Pinus no sul do Brasil foi um processo instituído pela estratégia de desenvolvimento do país nas décadas de 60 e 70 . Atualmente, a base de florestas plantadas para a produção de madeira sustenta uma cadeia produtiva que tem participação fundamental na economia do país. Embora algumas espécies do gênero Pinus sejam tidas como exóticas invasoras, elas contribuem ambiental, social e economicamente para o desenvolvimento da região Sul do Brasil, dadas as características do processo de plantio e manejo, o qual é sustentável e enquadra-se nas prerrogativas da coalisão global para o "Desenvolvimento Sustentável". A necessidade atual é a de formalizar uma regulação para amenizar os efeitos negativos da regeneração natural das espécies do gênero Pinus, devido às características e a alta adaptabilidade às condições edafoclimáticas regionais. Palavras-chave: Desenvolvimento sustentável; silvicultura; Pinus; Sul do Brasil.
\end{abstract}

\begin{abstract}
Synthesis of the genus Pinus contribution for the sustainable development in the south of Brazil. The silviculture of the genus Pinus in the South of Brazil was a process stablished as a development strategy for the country in the 60's and 70's. Nowadays these man-made forests for wood production maintain a productive chain which has a fundamental participation for the country's economy. Although some of the specie of the genus Pinus are being classified as exotic and considered dangerous for our natural environment (biological contamination), these species contribute for the environment, social and economic development in the South of Brazil, given the characteristics of the process of the silviculture and management techniques which is sustainable and is included in a global coalition for the "Sustainable Development". The actual necessity is to stablish a regulation to slow down the effects of the natural regeneration of the genus Pinus due to their characteristics and their high adaptability to our regional edaphic and climate conditions.

Keywords: Sustainable development; silviculture, genus pinus; south of Brazil.
\end{abstract}

\section{INTRODUÇÃO}

As duas principais espécies do gênero Pinus plantadas na região sul do Brasil, P. elliottii Engelm. e $P$. taeda $L$., tiveram excelente adaptabilidade às condições edafoclimáticas. Com relação à adaptabilidade e comportamento dessas espécies, Ziller (2000) considera que, dentre as espécies do gênero Pinus já comprovadas como altamente invasoras em outros países, está Pinus elliottii, conforme declaração oficial da África do Sul (HENDERSOM, 1995).

Entretanto, o uso e aplicação da madeira do gênero Pinus nas últimas três décadas cresceu substancialmente transformando-a em matéria-prima fundamental para movimentar um setor produtivo de relevante importância para a economia brasileira. Segundo Siqueira (2003), as florestas plantadas no Brasil atingem 4,9 milhões de hectares, o que corresponde a $0,9 \%$ da cobertura florestal total do país. Na região Sul do Brasil, a área plantada com o gênero Pinus é de 1.060 .050 hectares, correspondendo a $57,6 \%$ da área total, desse gênero, plantada no país (SIQUEIRA, 2003). É digno de ressalva que a área total plantada com o gênero Pinus representa $1,74 \%$ da superfície territorial da região Sul. 
A condição atual de uso e aplicação do gênero Pinus como espécie sustentadora de uma cadeia produtiva importante para a região Sul e para o país implica compreender melhor a função de suas espécies ao longo do processo econômico, social e ambiental.

O crescimento dos processos de demanda que provocaram a evolução tecnológica e industrial das últimas três décadas do século XX foi o mentor de uma nova conjuntura, ou seja, desencadeou uma nova visão relativa ao homem e seus efeitos sobre o planeta. Isso foi consolidado por uma coalisão global, gerida por diversos eventos promovidos pela Organização das Nações Unidas, a qual promulgou uma nova ordem, um desafio global acerca dos eventos provocados pela demanda humana: "O Desenvolvimento Sustentável". Sob a temática do "Desenvolvimento Sustentável" está também proclamado o Triple Botton Line, que associa os conceitos de sustentabilidade ao de um compromisso da sociedade e das empresas, não somente para a evolução de seus indicadores econômicos e financeiros, mas também das suas ações sociais e no meio ambiente. Nesse sentido, as atividades produtivas e transformadoras que servem a sociedade e promovem a economia e o desenvolvimento deverão estar sintonizadas em três pontos distintos: a viabilidade econômica, a responsabilidade social e a responsabilidade ambiental.

O contexto do momento global coloca a silvicultura e o manejo florestal como atividades desafiadoras para constituir o "Desenvolvimento Sustentável", uma vez que tais práticas estão fundamentadas no "Sistema de Assimilação e Redução Natural", compreendido por Hosokawa et al. (1998) como indicador de que a floresta é uma unidade produtora e que pode ser conduzida pelo critério do manejo sob o regime de rendimento sustentado. Nesse sentido, especialmente o reflorestamento com o gênero Pinus passa a ser um processo de relevante interesse para a coalizão global, para os princípios mais atuais que imperam na busca do "Desenvolvimento Sustentável" e do atendimento aos fundamentos do Triple Botton Line. Portanto, o reconhecimento de que a participação do gênero Pinus propicia as práticas de uma silvicultura e manejo florestal como atividades alinhadas ao "Desenvolvimento Sustentável" é mera conseqüência do foco da própria atividade florestal realizada dentro de princípios técnicos e éticos adequados à realidade da região Sul do Brasil e da economia de mercado envolvendo a madeira.

\section{A SILVICULTURA DO GÊNERO Pinus NO SUL DO BRASIL}

A silvicultura do gênero Pinus no sul do Brasil tem seu ponto inicial marcado pelo advento do incentivo fiscal, uma diretriz estratégica dos anos 60 e 70 para o desenvolvimento do país. Em recente trabalho de pesquisa, Siqueira (2003) relata que a criação do Instituto Brasileiro de Desenvolvimento Florestal, em 1967, surgiu em um cenário de necessidade crescente de regulamentação do Setor Florestal, sendo uma das principais responsabilidades do novo órgão o gerenciamento do programa de incentivos fiscais para o reflorestamento, instituído pela Lei 5.106, de 1966. O mesmo autor, citando STCP (2001), enfatiza que o reflorestamento executado a partir dos incentivos fiscais propiciou - nas regiões Sul e Sudeste $-\mathrm{o}$ ressurgimento da indústria de base florestal. A disseminação dos plantios florestais com o gênero Pinus no sul do Brasil deu-se inicialmente sob a conduta do Incentivo Florestal, o que na época implicava na concessão de recursos para áreas determinadas como "Distritos Florestais", privilegiando terras de menor potencial produtivo.

Siqueira (2003) concluiu, em trabalho de pesquisa, que em nenhum lugar do mundo se questiona a importância das florestas e a sua fundamental responsabilidade em gerar bens e benefícios para as populações que dependem direta ou indiretamente dos recursos delas oriundos. Entretanto, o mesmo autor coloca que, no Brasil, é notório que a sociedade civil, através das organizações não-governamentais, tem adotado cada vez mais uma postura voltada à preservação das florestas, muitas vezes em detrimento das respostas econômicas e sociais. Nesse sentido, vale mencionar a imagem propagada das espécies exóticas, notadamente as do gênero Pinus, como sendo prejudiciais ao meio ambiente.

A condição da silvicultura do gênero Pinus no Sul do Brasil, sob a ótica da possibilidade de agressão ao meio ambiente, foi evidenciada por Ziller (2000) em análise da ocorrência de contaminação por espécie exótica e ações antrópicas no ecossistema da Estepe Gramíneo-Lenhosa na região de Ponta Grossa, Palmeira, Balsa Nova e Campo Largo, no estado do Paraná. Isso posto, ficou constatado que o gênero Pinus, frente aos ecossistemas abertos, como a Estepe Gramíneo-Lenhosa do Segundo Planalto Paranaense, tem facilidade de expansão, pela adaptabilidade, e assim realmente torna-se ocupante de 
espaços livres e propícios à sua regeneração. Não obstante, trata-se de uma cultura regulada pelo homem, o que permitirá, sem dúvida, um absoluto e eficiente controle do processo reprodutivo natural. Portanto, vale enfatizar que a regulação de tal processo pode ser realizada pelo desenvolvimento de uma legislação específica que empregue como base as diretrizes da União Internacional para a Conservação da Natureza (IUCN, 2000), citadas por Ziller (2000) em suas conclusões.

\section{CONTRIBUIÇÃO DO GÊNERO Pinus SOB A ÓTICA AMBIENTAL}

O momento atual, início do século XXI, promove o "Desenvolvimento Sustentado", conforme supramencionado, e a silvicultura e manejo do gênero Pinus, no Sul do Brasil, estão focados nas premissas da sustentabilidade do processo produtivo de madeira em consonância com o Triple Botton Line, o que é evidenciado pelas certificações especializadas e pelo próprio arcabouço legal vigente. A certificação do Forest Stewardship Council (FSC), em seus princípios e critérios, evidencia a necessidade da prática do manejo florestal sustentável atrelado ao Triple Botton Line, assim como outros padrões de certificações confirmam a necessidade de tal requisito.

A contribuição das formações florestais produtivas, os reflorestamentos com espécies do gênero Pinus, também é significativa na conservação do solo, como cultura de longo prazo e como atividade de baixo impacto ambiental. Souza et al. (1982), em pesquisa intitulada "Retenção de água em duas unidades de solos sob floresta de Pinus elliottii em campo nativo", concluíram que, sob o Pinus, o solo apresentou uma maior capacidade de armazenamento de água, provavelmente devido ao tipo de matéria adicionada, no caso originada das acículas.

Daros (1982), analisando as alterações provocadas pelo reflorestamento de Pinus elliottii na fertilidade de dois tipos de solos na região da Lapa, estado do Paraná, teve como conclusão que o Pinus promoveu a redistribuição da matéria orgânica, aumentando o teor em profundidade nas duas unidades de solo sem, no entanto, alterar o teor total do solo. Na mesma linha de pesquisa, Kahil (1986), analisando as alterações na matéria orgânica do solo causadas por reflorestamento de Pinus elliottii na região da Lapa, concluiu que os resultados do fracionamento da matéria orgânica do solo não indicaram efeitos prejudiciais para o reflorestamento relativos a esse parâmetro, sendo até possível que essa cobertura venha, ao longo do tempo, a favorecer o acúmulo de matéria orgânica nos perfis do solo. Em outra pesquisa, Reissmann (1996), utilizando Pinus taeda no município de Campina Grande do Sul, a $70 \mathrm{~km}$ de Curitiba, estado do Paraná, para recuperação de área degradada, em análise aos 16 anos de idade do plantio, concluiu que a espécie adaptou-se muito bem às condições do sítio degradado, porém o solo ainda não pôde ser considerado recuperado apesar de se verificar um enriquecimento de 8,5 vezes mais matéria orgânica em relação à condição inicial nos primeiros $5 \mathrm{~cm}$ de solo. Assim, fica evidente a contribuição do gênero Pinus na conservação do solo.

Como processo produtivo, a silvicultura do gênero Pinus tem como foco a produção da madeira em toras para alimentar a cadeia produtiva da madeira, o que minimizou substancialmente o impacto ambiental da pressão sobre as formações florestais nativas. A demanda por produtos de madeira é um processo fomentador da exploração florestal, entretanto, com o manejo adequado e a expansão da base de reflorestamento, o processo produtivo orientado por técnicas garantirá a sustentabilidade no atendimento das demandas, permitindo o equacionamento do uso da matéria-prima madeira sem atingir as formações florestais naturais.

Segundo Rocha (2002), o Brasil poderá assumir posição privilegiada junto aos países que buscam reverter o processo de mudança climática global, tanto do ponto de vista das reduções de emissões, evitando as queimadas, como em projetos de seqüestro de carbono, através de reflorestamentos. Isso inclui potencialmente o gênero Pinus para a região Sul do Brasil. Ainda nesse contexto, Schlamadinger (1996), citado por Nutto et al. (2002), desenvolveu um modelo para o seqüestro de carbono, o modelo "A", o qual assume como premissa o reflorestamento em área onde não existe floresta, sendo o estoque de carbono igual a zero, considerando o modelo short rotation forestry, no qual estão incluídas as espécies dos gêneros Pinus e Eucalyptus.

A prática da silvicultura com o gênero Pinus no Sul do Brasil tem sido desenvolvida ao longo dos últimos trinta e cinco anos de forma a implementar conceitos e técnicas, adequando os processos para a minimização dos impactos ambientais. Vale considerar ser ela uma cultura que não utiliza insumos químicos em proporções representativas e que a redução, com tendência a zero, dos procedimentos como 
queimadas, já é uma realidade. Também o óleo lubrificante para motosserras é à base de extrativos vegetais de plantas oleaginosas e reciclado, sendo totalmente biodegradável e atóxico. Assim, pode ser enquadrada a atividade da silvicultura com o gênero Pinus, no Sul do Brasil, como atividade limpa e de baixo impacto ambiental.

\section{CONTRIBUIÇÃo DO GÊNERO Pinus SOB A ÓTICA ECONÔMICA}

A cadeia produtiva da madeira no Brasil é relevante e importante para a economia nacional, pois tem participação de aproximadamente $4,1 \%$ do PIB (SBS, 2001). Nessa cadeia produtiva estão os setores madeireiro, moveleiro, de papel e celulose, de chapas reconstituídas, a produção de madeira para o consumo da siderurgia e a produção de carvão vegetal. Segundo Siqueira (2003), o faturamento total da área florestal equivaleu a US\$ 23 bilhões em 2000, dados referenciados por STCP (2001), e gerou US\$ 5,4 bilhões na exportação, o que equivale a $10 \%$ de toda a exportação brasileira, gerando US\$ 2,0 bilhões em impostos SBS (2001) e mais de 2,0 milhões de empregos diretos e indiretos. Ainda Siqueira (2003), citando STCP (2001), coloca a distribuição do faturamento setorial da seguinte forma:

- Celulose e papel - US\$ 7,5 bilhões

- Móveis de madeira - US\$ 7,3 bilhões

- $\quad$ Siderurgia e carvão vegetal - US\$ 4,2 bilhões

- Madeira sólida e painéis reconstituídos - US\$ 4,0 bilhões

Siqueira (2003) indica que o consumo dos segmentos industriais de base florestal foi de 170 milhões de $\mathrm{m}^{3}$, com base em STCP (2001), e o gênero Pinus participou com aproximadamente 40 milhões de $\mathrm{m}^{3}$.

Em termos de números, volumes e cifras, é notória a importância do gênero Pinus como base de sustentação de uma economia setorial que possui significância para a economia nacional. A movimentação de recursos de monta significativa e a dimensão da importância do setor produtivo de madeira roliça, o setor reflorestador, junto à cadeia produtiva da madeira e às demandas agregadas, são vitais para a economia regional e nacional.

\section{CONTRIBUIÇÃO DO GÊNERO Pinus SOB A ÓTICA SOCIAL}

A prática da silvicultura com o gênero Pinus, na região Sul do Brasil, ao longo dos últimos trinta e cinco anos, contribuiu para a mudança socioeconômica de diversas regiões, pois permitiu a expansão da indústria de base florestal. Como principais pólos, figuram as indústrias de papel da região do norte velho paranaense, especialmente a KLABIN Papel e Celulose, a PISA Papel de Imprensa S.A. (atual NORSKE SKOG), a INPACEL, a SENGÉS Papel e Celulose e a IGUAÇU Celulose. Ainda pode ser acrescentada toda a expansão do setor de papel e celulose em Santa Catarina e no Rio Grande do Sul.

A base florestal plantada com o gênero Pinus também atraiu novos investimentos e novas tecnologias, tais como as fábricas de chapas reconstituídas, a TAFISA e a MASISA no Paraná, e a SATIPEL e FIBRAPLAC no Rio Grande do Sul.

Outro setor importante que aderiu à evolução tecnológica e ao uso e aplicação da madeira do gênero Pinus foi o setor moveleiro, as indústrias de móveis e componentes de madeira, tais como painéis e molduras, especialmente no planalto norte de Santa Catarina, no norte novo do Paraná e no pólo moveleiro de Bento Gonçalves, no Rio Grande do Sul.

Da mesma forma que a expansão industrial trouxe o desenvolvimento social e econômico, a atividade de reflorestamento avançou conceitualmente em termos de processo de gestão. Com a necessidade de adequação à percepção do mercado global, houve um aprimoramento das técnicas e das relações com os colaboradores e com a comunidade. Os preceitos componentes das certificações de diversas naturezas provocaram a necessidade de qualificar pessoas, comunicar-se com as comunidades e desenvolver parcerias de ordem social. Isso promoveu a melhoria da qualidade vida em cada pólo de desenvolvimento florestal, envolvendo as empresas, as representações políticas e as comunidades.

A evidência de que, nas últimas três décadas de atividade florestal, a silvicultura com o gênero Pinus no Sul do Brasil contribuiu para o desenvolvimento social é notória pelo próprio reflexo dos números da economia da cadeia produtiva da madeira anteriormente abordados. 


\section{CONSIDERAÇÕES FINAIS}

Mesmo o gênero Pinus tendo algumas espécies enquadradas como exóticas invasoras, é notório que o processo agressivo dá-se em relação a ecossistemas abertos e frágeis, e que tais espécies são atualmente componentes de um sistema socioeconômico que contribui para a manutenção do desenvolvimento da região Sul e de toda uma cadeia produtiva no Brasil.

A prática da silvicultura do Pinus na região Sul do Brasil é um processo de baixo impacto ambiental e por suas características técnicas promove a proteção do solo e a redução a zero da pressão pela exploração dos remanescentes florestais nativos, podendo ainda ser uma oportunidade para o seqüestro de carbono.

Os processos de certificação têm a proposição de efetuar a condução da silvicultura e manejo das florestas produtivas plantadas com o gênero Pinus de forma a exercer técnicas que garantam o controle da disseminação da espécie, ou seja, realizando a mitigação da possível contaminação que algumas espécies do gênero possam acarretar. Isso já é um procedimento factível e de fácil sistematização junto às funções operativas da silvicultura do gênero Pinus.

A silvicultura e o manejo florestal dos maciços formados por Pinus são passíveis de sustentabilidade, no sentido de integrar processos e atender os princípios do "Desenvolvimento Sustentável", tornando-se atividade contribuinte na sociedade brasileira.

A prática da atividade de reflorestamento com o gênero Pinus no Sul do Brasil, devidamente estruturada em técnicas, possui ciclo de longo prazo e promove o desenvolvimento social e econômico em extensão regional e tem participação extremamente importante na economia nacional, especialmente porque a amplitude da atividade promove e concilia o Triple Botton Line às práticas de rotina, consolidando uma atividade economicamente viável, ambientalmente correta e socialmente justa.

\section{RECOMENDAÇÕES}

Para melhorar a eficiência da silvicultura e o manejo do gênero Pinus no Sul do Brasil, há a necessidade de serem promovidos mecanismos para disseminação de técnicas que garantam o processo embasado no Triple Botton Line, através de certificações e auditorias técnicas sistemáticas.

A prática regular da silvicultura do gênero Pinus em grande escala deverá contar com procedimentos formais, processos e métodos para o controle da dispersão da semente ou da capacidade de invasão das espécies em ambientes susceptíveis.

O processo de silvicultura e manejo do gênero Pinus no Sul do Brasil deverá ser objeto de pesquisa visando consolidar técnicas e procedimentos que garantam o "Desenvolvimento Sustentável" para a cadeia produtiva da madeira, confirmando as contribuições significativas de ordem econômica, social e, notadamente, ambiental.

\section{REFERÊNCIAS}

DAROS, E. Alterações provocadas pelo florestamento de Pinus elliottii na fertilidade de dois solos na região da Lapa-PR. 95 f. Dissertação (Mestrado em Engenharia Florestal) - Universidade Federal do Paraná, Curitiba, 1982.

HENDERSON, L. Plant invaders of South Africa - a pocket field guide to the identification of 161 of the most important and potentially important alien species. Pretoria: Agricultural Research Council, 1995. 177 p. (Plant Protection Research Institute Handbook, n. 5).

HOSOKAWA, R. T.; MOURA, J. B.; CUNHA, U. S. Introdução ao manejo e economia de florestas. Curitiba: Editora da UFPR, 1998. 162 p.

KAHIL, A. L. E. Análise das alterações na matéria orgânica do solo causadas pelo reflorestamento com Pinus elliottii na região da Lapa-PR. 196 f. Dissertação (Mestrado em Engenharia Florestal) Universidade Federal do Paraná, Curitiba, 1986 
NUTTO, L.; WATZLAWICK, L. F.; GRAMMEL, R.; FENNER, P. T. O mercado internacional de $\mathrm{CO}_{2}$ : o impacto das florestas naturais e das plantações. In: As florestas e o carbono. Curitiba: Imprensa Universitária da UFPR, 2002. p. 89-108.

REISSMANN, C. B. Contribuição do Pinus taeda na recuperação de solos degradados em áreas de empréstimo - um estudo de caso com horizontes orgânicos. In: Recuperação de Áreas Degradadas - III Curso de Atualização. Curitiba: FUPEF, 1996. p. 135-141.

ROCHA, M. T. O aquecimento global e os instrumentos de mercado para a solução do problema. In: As Florestas e o carbono. Curitiba: Imprensa Universitária da UFPR, 2002. p. 1-34.

SIQUEIRA, J. P. D. Os conflitos institucionais da gestão florestal no Brasil - um benchmarking entre os principais produtores florestais internacionais. $182 \mathrm{f}$. Tese (Doutorado em Engenharia Florestal) Setor de Ciências Agrárias, Universidade Federal do Paraná, Curitiba, 2003.

SOUZA, M. L. P.; SOUZA, D. M. P.; LUCCHESI, L. A. C. Retenção de água em duas unidades de solos sob floresta de Pinus elliottii e campo nativo. Revista do Setor de Ciências Agrárias, Curitiba, v. 4, p. 17-22, 1982.

ZILLER, S. R. A Estepe gramineo-lenhosa no segundo planalto do Paraná: diagnóstico ambiental com ênfase a contaminação biológica. $177 \mathrm{f}$. Tese (Doutorado em Engenharia Florestal) - Setor de Ciências Agrárias, Universidade Federal do Paraná, Curitiba, 2000. 